\title{
1 A high-throughput method for measuring critical thermal limits of 2 leaves by chlorophyll imaging fluorescence
}

4 Pieter A. Arnold ${ }^{1, *}$, Verónica F. Briceño ${ }^{1}$, Kelli M. Gowland ${ }^{1}$, Alexandra A. Catling ${ }^{1}$,

5 León A. Bravo ${ }^{2}$, Adrienne B. Nicotra ${ }^{1}$

$7 \quad{ }^{1}$ Division of Ecology and Evolution, Research School of Biology, The Australian National

8 University, Canberra, ACT, Australia

$9 \quad{ }^{2}$ Department of Agronomical Sciences and Natural Resources, Faculty of Agropecuary and

10 Forestry Sciences \& Center of Plant, Soil Interaction and Natural Resources Biotechnology,

11 Scientific and Technological Bioresource Nucleus, Universidad de La Frontera, Casilla 54D,

12 Temuco, Chile

14 *Corresponding author: Pieter A. Arnold, address: 46 Sullivans Creek Rd, Acton, ACT 2600,

15 Australia, email: pieter.arnold@anu.edu.au, phone: +6126125 2543

17 Running head: Leaf thermal limits using chlorophyll fluorimetry

19 Keywords: Chlorophyll fluorescence, cold tolerance, ecophysiology, physiological ecology, 20 temperature stress 


\section{Abstract}

22 Plant thermal tolerance is a crucial research area as the climate warms and extreme weather

23 events become more frequent. Leaves exposed to temperature extremes have inhibited

24 photosynthesis and will accumulate damage to photosystem II (PSII) if tolerance thresholds are

25 exceeded. Temperature-dependent changes in basal chlorophyll fluorescence $\left(T-F_{0}\right)$ can be used

26 to identify the critical temperature at which PSII is inhibited. We developed and tested a high-

27 throughput method for measuring the critical temperatures for PSII at low ( $\left.C T_{\mathrm{MIN}}\right)$ and high

$28\left(C T_{\mathrm{MAX}}\right)$ temperatures using a Maxi-Imaging fluorimeter and a thermoelectric Peltier plate

29 heating/cooling system. We examined how experimental conditions: wet $v s$ dry surfaces for

30 leaves and heating/cooling rate, affect $C T_{\mathrm{MIN}}$ and $C T_{\mathrm{MAX}}$ across four species. $C T_{\mathrm{MAX}}$ estimates

31 were not different whether measured on wet or dry surfaces, but leaves were apparently less

32 cold tolerant when on wet surfaces. Heating/cooling rate had a strong effect on both $C T_{\text {MAX }}$ and

$33 C T_{\mathrm{MIN}}$ that was species-specific. We discuss potential mechanisms for these results and

34 recommend settings for researchers to use when measuring $T-F_{0}$. The approach that we

35 demonstrated here allows the high-throughput measurement of a valuable ecophysiological

36 parameter that estimates the critical temperature thresholds of leaf photosynthetic performance

37 in response to thermal extremes. 


\section{Introduction}

39 Understanding both vulnerability and tolerance limits of plants to thermal extremes is a priority

40 for plant biology research as the Earth's climate continues to change, thereby exposing these

41 sessile organisms to increased thermal stress (O'Sullivan et al. 2017; IPCC 2018; Geange et al.

42 2021). Thermal stress disrupts and inhibits physiological processes (Goraya et al. 2017), induces

43 protective and repair mechanisms (Sung et al. 2003; Goh et al. 2012), leads to declines in plant

44 performance, and threatens survival (Zinn et al. 2010; Bita and Gerats 2013). Plant

45 photosynthesis is sensitive to thermal stress and has distinct limits beyond which photosynthetic

46 assimilation is inhibited and tissue damage can occur (e.g., Neuner and Pramsohler 2006;

47 Sukhov et al. 2017). The temperature sensitivity of photosynthesis is in part derived from the

48 thermally-dependent stability of protein-pigment complexes in the light harvesting complex II

49 (LHCII) of photosystem II (PSII) of the thylakoid membrane in chloroplasts (Ilík et al. 2003),

50 which are integral to the photosynthetic electron transport chain (Berry and Björkman 1980;

51 Allakhverdiev et al. 2008; Mathur et al. 2014).

52 Chlorophyll fluorimetry has become a widely used tool for assessing the thermal limits

53 of photosynthesis for both cold and heat tolerance (Geange et al. 2021). Chlorophyll can

54 dissipate absorbed light energy via photochemistry or re-emit it as heat energy or fluorescence

55 (Baker 2008; Murchie and Lawson 2013). A dark-adapted leaf exposed to a low-intensity

56 modulated measuring light, which does not induce electron transport, emits a minimal amount

57 of chlorophyll- $a$ fluorescence from LHCII, called $F_{0}$ (Yamane et al. 1997). Under more intense

58 or actinic light, processes that are highly dynamic and sensitive to other factors but not well

59 correlated with the viability of the photosynthetic tissue cannot be isolated from the

60 measurement of the temperature dependence (thermal stability) of chlorophyll fluorescence

61 (Schreiber et al. 1995; Logan et al. 2007). To assess the thermal stability limits of LHCII, plant

62 ecophysiologists typically measure the temperature-dependent change in basal chlorophyll- $a$

63 fluorescence $\left(T-F_{0}\right)$ to determine the critical temperature threshold $\left(T_{\text {crit }}\right)$, denoted by a sudden

64 increased in $F_{0}$ at which PSII begins to inactivate (e.g., Schreiber and Berry 1977; Berry and

65 Björkman 1980; Briantais et al. 1996; Knight and Ackerly 2002; Ilík et al. 2003; Hüve et al.

66 2006; Neuner and Pramsohler 2006; O'Sullivan et al. 2013; O'Sullivan et al. 2017; Zhu et al.

67 2018). $F_{0}$ is a fluorescence parameter that can be measured rapidly and continuously throughout

68 heating or cooling in darkness, without the need of a saturating pulse and re-dark adaptation as

69 for $F_{\mathrm{V}} / F_{\mathrm{M}}$ measurements that are commonly used to detect photosynthetic inhibition.

70 One critique of $T-F_{0}$ measurements and $T_{\text {crit }}$ determination is that they are conducted on

71 detached leaves. Detaching leaves to expose them to a precisely controlled and measured 
72 thermal surface is usually, but not always, a necessary component of this trait measurement.

73 While modern chlorophyll fluorescence imaging systems can be used on attached leaves,

74 simultaneously heating or cooling these leaves precisely while measuring multiple leaf samples

75 remains logistically complex, especially for ecological applications. Leaf detachment can affect

76 leaf hydration and fluorescence through reduced PSII activity, ionic leakage, and oxidations

77 compared to attached leaves (Potvin 1985; Smillie et al. 1987). Leaf dehydration could be

78 problematic for certain species if leaves are sampled long before they are assessed for $T_{\text {crit }}$ or if

79 they are measured as leaf sections or discs. To avoid dehydration during the $T-F_{0}$ measurement,

80 a wet surface, such as damp paper surface as in Knight and Ackerly (2002), could physically

81 impair evaporation by saturating the atmosphere surrounding the leaf. However, it is not clear

82 whether a wet surface interferes with the $T-F_{0}$ measurement or how it might affect the $T_{\text {crit }}$ value compared to using a dry surface.

A great advantage of using temperature-dependent changes in chlorophyll fluorescence and a thermoelectric plate is that both cold and heat tolerance limits of leaves can be measured with much of the same equipment. However, the protocol may need to be altered slightly because cold transitions in nature occur much more slowly than heat transitions, which may induce different mechanisms in response to thermal stress. For example, leaf temperature can rapidly increase during a lull in wind speed, far exceeding ambient temperature on a hot and sunny day (Vogel 2009; Leigh et al. 2012). On a cold frosty night, even considering air temperature stratification, the rate of leaf temperature cooling rarely exceeds $5^{\circ} \mathrm{C} \mathrm{h}^{-1}$, especially below freezing (Sakai and Larcher 1987). Therefore, the 'standard' protocols for measuring $T_{\text {crit }}$ typically change temperature much faster for heat tolerance than for cold tolerance. While this approach is justified by rates observed in natural systems, the first published application of the $T-F_{0}$ technique (Schreiber and Berry 1977) used an apparently arbitrary 'slow' heating rate of $1^{\circ} \mathrm{C}^{-1}$ (i.e., $60^{\circ} \mathrm{C} \mathrm{h}^{-1}$ ). Subsequently, while many studies followed suit, a vast range of

97 heating/cooling rates have been applied (see Table S1, available as Supplementary Material to

98 this paper), often with little justification. We have known for decades that different rates of 99 heating and cooling can affect the $T$ - $F_{0}$ curve and shift the $T_{\text {crit }}$ value by at least $2{ }^{\circ} \mathrm{C}$ (Bilger $e t$ 100 al. 1984; Frolec et al. 2008). Therefore, studies employing $T-F_{0}$ methods for measuring thermal 101 tolerance limits that use different heating/cooling rates might not be directly comparable, even 102 within a given species. Further, it is reasonable to expect that plant species might exhibit 103 different responses to variation in methodology. 
106 time as a thermoelectric Peltier plate with leaf samples is heated or cooled to thermal extremes.

107 We then investigate variations of easily controllable variables of the standard experimental

108 protocol that could affect thermal tolerance limit estimates. We sought to determine the effects

109 of wet $v s$ dry surface and heating/cooling rate on $T_{\text {crit }}$ estimates for both the heat tolerance limit

110 (hereafter referred to as critical maximum temperature; $C T_{\mathrm{MAX}}$ ) and the cold tolerance limit

111 (hereafter referred to as critical minimum temperature; $C T_{\mathrm{MIN}}$ ) of leaf thermal stability of

112 species with different growth forms. By comparing among these species, we also determined

113 whether the effects of the two experimental variables could be generalised for different growth

114 forms of plants that originate from different conditions. In doing so, we advise researchers on

115 what we consider to be a pragmatic approach to measuring leaf thermal tolerance using

116 chlorophyll imaging fluorescence, at a time when improved understanding of plant tolerance to

117 thermal extremes is needed for cultivated and wild species alike.

\section{Materials and Methods}

\section{Species description and leaf samples}

121 We chose plant species that represented diverse growth habits and leaf morphology (in surface

122 characteristics and leaf thickness) to make simple interspecific comparisons while testing the $T$ -

$123 \quad F_{0}$ method. Wahlenbergia ceracea Lothian (Campanulaceae) waxy bluebell is a small perennial

124 herb that is sparsely distributed across south-eastern Australia. We grew F2 generation

125 W. ceracea plants under controlled glasshouse conditions $\left(20 / 15^{\circ} \mathrm{C}\right.$ set day/night temperatures $)$

126 and leaves from mature plants were used for all experiments. Seed stock originated from

127 Kosciuszko National Park, NSW, Australia $\left(36.432^{\circ} \mathrm{S}, 148.338^{\circ} \mathrm{E}\right)$ that was collected in 2015

128 and 2016. Melaleuca citrina (Curtis) Dum. Cours. (Myrtaceae) common red bottlebrush were

129 used for all experiments. This species is native to south-eastern Australia but also distributed as

130 a cosmopolitan plant. Sampled individuals were growing as native shrubs at The Australian

131 National University, ACT, Australia (35.279 $\left.{ }^{\circ} \mathrm{S}, 149.118^{\circ} \mathrm{E}\right)$. Quercus phellos L. (Fagaceae)

132 willow oak trees were used only in the heat tolerance component of the surface wetness

133 experiment, prior to the abscission of leaves in autumn. This deciduous species is native to

134 North America and sampled individuals were growing as tall, shady ornamental trees at The

135 Australian National University, ACT, Australia $\left(35.277^{\circ} \mathrm{S}, 149.115^{\circ} \mathrm{E}\right)$. Escallonia rubra var.

136 'pink pixie' (Ruiz \& Pav.) Pers. (Escalloniaceae) pink escallonia were used for the cold

137 tolerance component of the surface wetness experiment and the heating/cooling rate experiment

138 in place of $Q$. phellos after the former shed its leaves. Escallonia rubra is native to South 
139 America and sampled individuals were growing as dense ornamental shrubs at The Australian

140 National University, ACT, Australia $\left(35.277^{\circ} \mathrm{S}, 149.117^{\circ} \mathrm{E}\right)$.

141 All measurements were taken between February and October 2019. Due to the variation

142 in species availability across experiments and the potential effects of seasonal change on

143 absolute tolerance values, we consider each experiment separately and do not draw comparisons

144 across surface wetness and heating/cooling rate experiments. Assays (surface wetness or

145 heating/cooling rates for heat or cold tolerance assays) were conducted on replicate days to

146 control for potential effects of day. Leaves selected for measurement were fully expanded,

147 visually free of damage and discolouration, and within two leaf pairs of a growing stem tip on

148 an intact and healthy stem. Although leaf age could not be determined directly, these criteria

149 allowed us to select leaves from the same cohort and of similar condition. Leaves were excised

150 between 0900 and 1300 hours, placed in sealed bags, and then taken to the lab in an insulated

151 container, where they were always used for $T-F_{0}$ measurements within 30 minutes of initial

152 collection.

153

\section{Temperature-dependent change in chlorophyll fluorescence $\left(T-F_{0}\right)$ measurement}

155 Leaf samples were attached to white filter paper $(125 \times 100 \mathrm{~mm})$ with double-sided tape. We

156 placed the filter paper with leaves on a Peltier plate (CP-121HT; TE-Technology, Inc.,

157 Michigan, USA; $152 \times 152 \mathrm{~mm}$ surface) that was controlled by a bi-polar proportional-integral-

158 derivative temperature controller (TC-36-25; TE-Technology, Inc.) and powered by a fixed-

159 voltage power supply (PS-24-13; TE-Technology, Inc.). The Peltier plate uses four direct-

160 contact thermoelectric modules that can both cool and heat the plate, which with a MP-3193

161 thermistor (TE-Technology, Inc.) the plate had potential thermal limits of $-20^{\circ} \mathrm{C}$ and $100^{\circ} \mathrm{C}$.

162 LabVIEW-based control software (National Instruments, Texas, USA) was adapted to control

163 heating or cooling rate using source code available from TE-Technology, Inc. based on the

164 supplied user interface. The Peltier plate maintained a stable set temperature within $\pm 0.1^{\circ} \mathrm{C}$

165 (precision) and $\pm 1{ }^{\circ} \mathrm{C}$ tolerance across the plate surface. We attached two type-T thermocouples

166 to the underside of two randomly selected leaves on the plate as representative measures of leaf

167 temperatures. Thermocouple temperature data were recorded every $10 \mathrm{~s}$ by a dual-channel data

168 logger (EL-GFX-DTC; Lascar Electronics Ltd., Salisbury, UK) and the mean temperature of the

169 two thermocouples was used for all leaf temperature calculations. Because the two

170 thermocouples measured temperatures of two single leaves per experimental run, we were able

171 to extract a small subset of ice nucleation temperatures (NT) using the temperature of the first

172 exothermic reaction in cold tolerance assays. The Peltier plate assembly height was controlled 
173 by a laboratory scissor-jack to fit within an aluminium frame at an ideal height below the

174 fluorescence camera (Fig. 1a). Heavy double-glazed glass was placed on top of the leaf samples

175 on the plate to compress samples against the plate surface to ensure maximum contact and

176 create a thermal buffer to ensure close matching of leaf and plate temperatures. In addition to

177 greater thermal buffering relative to standard glass, double-glazed glass avoids condensation

178 that might lead to erroneous measurements of $F_{0}$. All areas of both the Peltier plate and glass

179 that were outside of the filter paper area were blacked out with heat-resistant black electrical

180 tape to remove ambient light reflection and interference.

We used a Pulse Amplitude Modulated (PAM) chlorophyll fluorescence imaging system

182 (Maxi-Imaging-PAM; Heinz Walz GmbH, Effeltrich, Germany) mounted $185 \mathrm{~mm}$ above the

183 Peltier plate (imaging area of approximately $120 \times 90 \mathrm{~mm}$ ) to measure fluorescence parameters.

184 A weak blue pulse modulated measuring light $\left(0.5 \mu \mathrm{mol}\right.$ photons $\left.\mathrm{m}^{-2} \mathrm{~s}^{-1}\right)$ was applied

185 continuously at low frequency $(1 \mathrm{~Hz})$ to measure basal chlorophyll fluorescence $\left(F_{0}\right)$ from the

186 LHCII without driving PSII photochemistry. A red Perspex hood filtered ambient light from the

187 samples and the camera, and the entire Maxi-Imaging-PAM assembly was covered by thick

188 black fabric so that all measurements were made in darkness. Leaves were dark adapted for

18930 minutes to oxidise all PSII acceptors and obtain the basal $F_{0}$ values and then a single

190 saturating pulse at $10,000 \mu \mathrm{mol}$ photons $\mathrm{m}^{-2} \mathrm{~s}^{-1}$ was applied for $720 \mathrm{~ms}$ to determine the

191 maximal fluorescence $\left(F_{\mathrm{M}}\right)$ when the photosystem reaction centres are closed. Variable

192 fluorescence $\left(F_{\mathrm{V}}\right)$ was calculated as $F_{\mathrm{M}}-F_{0}$ and the relative maximum quantum yield of PSII

193 photochemistry $\left(F_{\mathrm{V}} / F_{\mathrm{M}}\right)$ was derived. $F_{\mathrm{V}} / F_{\mathrm{M}}$ is frequently used as a rapid measurement of stress

194 or relative health of leaves, where optimal $F_{\mathrm{V}} / F_{\mathrm{M}}$ values of non-stressed leaves are around 0.83

195 (Baker 2008; Murchie and Lawson 2013). Because our intention was to compare methods, we

196 aimed for a uniform sample of leaves, and therefore we used $F_{\mathrm{V}} / F_{\mathrm{M}}$ values $>0.65$ to subset data

197 to exclude any damaged leaves and focus on the $T-F_{0}$ of only healthy leaves. This conservative

198 sample exclusion process resulted in some experimental conditions or species with uneven and

199 lower sample sizes.

200 In each assay, we selected circular areas of interest that were as large as could fit within

201 the boundaries of each leaf using the Maxi-Imaging-PAM software, such that the $F_{0}$ values were

202 measured on the widest part of each leaf. One minute after measuring $F_{\mathrm{V}} / F_{\mathrm{M}}$, the

203 heating/cooling program was started simultaneously with the continuous recording of $F_{0}$ values

204 at set intervals with specifics varying depending on duration of the assay reflecting memory

205 capacity limits of the Maxi-Imaging-PAM (see below). For hot $T$ - $F_{0}$ measurements, the initial

206 set temperature held for dark adaptation of the leaves and $F_{\mathrm{V}} / F_{\mathrm{M}}$ was $20^{\circ} \mathrm{C}$, which was then 
207 heated to $60^{\circ} \mathrm{C}$ at varying rates (see heating/cooling rate experiment). For cold $T-F_{0}$

208 measurements, the assays were conducted in a cold room (set temperature: $4 \pm 2^{\circ} \mathrm{C}$ ) so that the

209 Peltier plate could reach $-20^{\circ} \mathrm{C}$. At ambient room temperatures of $\sim 20-22^{\circ} \mathrm{C}$, the Peltier plate

210 can reach approximately $-14^{\circ} \mathrm{C}$ before the plate heat output restrains cooling capacity. The

211 initial set temperature held for dark adaptation of the leaves and $F_{\mathrm{V}} / F_{\mathrm{M}}$ was $4{ }^{\circ} \mathrm{C}$, which was then

212 cooled down to $-20^{\circ} \mathrm{C}$.

213 The $T-F_{0}$ curve produced by heating/cooling the Peltier plate (and leaf samples) is

214 characterised by a stable or slow-rise in $F_{0}$ values until a critical temperature threshold where

215 there is a fast rise in $F_{0}$. With temperature on the $x$-axis and $F_{0}$ on the $y$-axis, the inflection point

216 of extrapolated regression lines for each of the slow and fast rise phases of the temperature-

217 dependent chlorophyll fluorescence response is the critical temperature, $T_{\text {crit }}$ (Knight and

218 Ackerly 2002; Neuner and Pramsohler 2006). The term $T_{\text {crit }}$ is ambiguous outside of this context

219 when both hot and cold thermal tolerance assays are conducted within the same study.

220 Hereafter, we refer to $T_{\text {crit }}$ only as the temperature extrapolated at the inflection point, and

221 elsewhere use accepted nomenclature used in thermal biology, $C T_{\mathrm{MAX}}$ and $C T_{\mathrm{MIN}}$, as upper

222 (heat) and lower (cold) thermal limits of leaf thermal tolerance (e.g., Sinclair et al. 2016; Janion-

223 Scheepers et al. 2018). Figure 1 presents representative $T-F_{0}$ curves and the calculations of $T_{\text {crit }}$

224 values for freezing leaves, where the fast rise phase occurs abruptly (Fig. 1b), and for heating

225 leaves where the fast rise phase is relatively gradual (Fig. 1c). The inflection point was

226 calculated using a break-point regression analysis of the mean leaf temperature estimated from

227 two thermocouples attached to leaves on the plate and relative $F_{0}$ values using the segmented $\mathrm{R}$

228 package (Muggeo 2017) using the R Environment for Statistical Computing (R Core Team

229 2020). We provide example files and example $\mathrm{R}$ code for extracting $T_{\text {crit }}$ values from $T$ - $F_{0}$

230 curves at https://github.com/pieterarnold/Tcrit-extraction.

\section{Surface wetness experiment: effect of wet vs dry surfaces for leaves on $C_{M I N}$ and $\mathrm{CT}_{M A X}$}

233 Most experiments that measure $T-F_{0}$ have measured leaf samples with all excess surface

234 moisture removed, on a dry surface. However, maintaining water content of detached leaves by

235 providing a wet surface where leaves were placed on top could be a viable way to facilitate

236 water uptake and keep leaf samples hydrated. In our experiment, leaves were placed on a filter

237 paper surface. For the wet surface treatment, leaves were placed as described above and then the

238 filter paper was saturated with MilliQ water-soaked paper towels with excess water absorbed

239 with dry paper towel thereafter. We compared $T-F_{0}$ curves and $T_{\text {crit }}$ estimates for both heat and

240 cold tolerance assays at a heating/cooling rate of $60^{\circ} \mathrm{C} \mathrm{h}^{-1}$ where leaves were placed on top of 
241

242

243

244

245

246

247

248

249

250

251

252

253

254

255

256

257

258

259

260

261

262

263

264

265

266

267

268

269

270

271

272

273

274

either wet or dry filter paper surfaces. A small subset of leaves on wet and dry surfaces were also measured for $C T_{\text {MIN }}$ and $N T$ at $15^{\circ} \mathrm{C} \mathrm{h}^{-1}$ in addition to the $60^{\circ} \mathrm{C} \mathrm{h}^{-1}$ experiment.

\section{Heating/cooling rate experiment: effect of heating/cooling rate on $C_{M A X}$ and $C T_{M I N}$}

Studies on thermal tolerance limits vary substantially in their set heating/cooling rate (Table S1), ranging from 30 to $>600^{\circ} \mathrm{C} \mathrm{h}^{-1}$ in studies on heat tolerance limits $\left(C T_{\mathrm{MAX}}\right)$ and from 1 to $10^{\circ} \mathrm{C} \mathrm{h}^{-1}$ in studies on cold or freezing tolerance limits $\left(C T_{\mathrm{MIN}}\right)$. The difference in magnitude between heat and cold tolerance limits reflects differences in natural potential rates of heating and cooling, where leaves may rapidly increase in temperature $\left(>240^{\circ} \mathrm{C} \mathrm{h}^{-1}\right.$ for a short period (Vogel 2009)) but cooling occurs far more slowly (rarely exceeding $5^{\circ} \mathrm{C} \mathrm{h}^{-1}$ (Buchner and Neuner 2009)). It stands to reason that the more than 10-fold difference in heating or cooling rates used among studies would affect the estimates and thus comparability of $T_{\text {crit, }}$ but this effect is not well understood. We chose a wide range of heating/cooling rates for both hot and cold with the aim to determine how the $T_{\text {crit }}$ estimate for $C T_{\mathrm{MIN}}$ and $C T_{\mathrm{MAX}}$ changes with heating/cooling rate. We compared $T-F_{0}$ curves and $T_{\text {crit }}$ estimates from different heating/cooling rates for both heat $\left(6,15,30,45,60,120,240^{\circ} \mathrm{C} \mathrm{h}^{-1}\right)$ and cold $\left(3,6,15,30,60,240^{\circ} \mathrm{C} \mathrm{h}^{-1}\right)$ tolerance assays where the filter paper was dry, and measurements were conducted in darkness. For 240,60 , and $30^{\circ} \mathrm{C} \mathrm{h}^{-1}$ heating/cooling rates, $F_{0}$ was recorded at $10 \mathrm{~s}$ intervals, $20 \mathrm{~s}$ for 15 and $6^{\circ} \mathrm{C} \mathrm{h}^{-1}$ heating/cooling rates, and $30 \mathrm{~s}$ for $3{ }^{\circ} \mathrm{C} \mathrm{h}^{-1}$ heating/cooling rates due to the 1000 record limit after which the Maxi-Imaging-PAM software stops recording.

\section{Statistical analyses}

The dataset was trimmed by removing leaves that had initial $F_{\mathrm{V}} / F_{\mathrm{M}}$ values below 0.65 , which was a value chosen to identify and remove unhealthy or damaged leaves, hence sample sizes varied among species and experimental conditions. Summary data (mean \pm standard error) is reported in Table S2. Data that matched conditions used in all experiments were used for multiple analyses (e.g., hot assay, heating/cooling rate of $60^{\circ} \mathrm{C} \mathrm{h}^{-1}$, dry filter paper could be used for all). Linear regression models were implemented using the stats package in the $\mathrm{R}$ environment for statistical and graphical computing (v3.5.1) (R Core Team 2020). Models were specified with $C T_{\mathrm{MIN}}$ or $C T_{\mathrm{MAX}}$ as the response variable and fixed categorical predictors of either wet/dry or heating/cooling rate depending on the experiment. $F_{\mathrm{V}} / F_{\mathrm{M}}$ was always included as a fixed covariate. We first fit models combining the three species for a given experiment, and then we fit species-specific models. Preliminary models were linear mixed effects regression models that included individual plant as a random factor, but in almost all cases, the term 
275

276

277

278

279

280

281

282

283

284

285

286

287

288

289

290

291

292

293

294

295

296

297

298

299

300

301

302

303

304

305

306

307

308

explained essentially zero variance, so we removed the random term in favour of a simpler linear model. Tables report model parameter estimates with statistical significance at $p<0.05$ indicated in bold and with * symbols. Supplementary tables (Tables S3-S6) report full statistical model output. Figures show means with non-parametric bootstrapped 95\% confidence intervals (95\% CIs) derived from the Hmisc R package (Harrell 2019). Finally, predicted temperature threshold estimates were modelled as a quadratic function of heating/cooling rate treated as a continuous variable for visualisation purposes. The data that support the findings of this study are openly available in the figshare repository: $10.6084 / \mathrm{m} 9$.figshare.12545093.

\section{Results}

\section{Overview}

The Peltier plate and chlorophyll fluorescence Maxi-Imaging-PAM system allows us to measure $T$ - $F_{0}$ (Fig. 1) on many leaves simultaneously. In these experiments, we measured up to 30 whole leaf samples in a single experimental run, which could take as little as 90 minutes including dark adaptation, leaf set up on the surface, and the temperature heating/cooling rate (at $60^{\circ} \mathrm{C} \mathrm{h}^{-1}$ ). The Peltier plate can easily accommodate a much greater number of smaller leaves, leaf discs, or leaf sections for even higher throughput phenotyping if required (Fig. S1).

\section{Surface wetness experiment: effect of wet vs dry surface for leaves on $C_{M I N}$ and $C T_{M A X}$}

The effect of water saturating the filter paper was clearly apparent for $T_{\text {crit }}$ value estimates for $C T_{\text {MIN }}$ (Fig. $2 a$ ) but not $C T_{\text {MAX }}$ (Fig. $2 b$ ). For all species combined and when the three species were analysed separately, $C T_{\mathrm{MIN}}$ values were significantly and consistently less negative (less cold tolerant) for leaves on wet surfaces than on dry ones, by $3-4^{\circ} \mathrm{C}$ (Table 1, S3, Fig. $2 a$ ). Variation in $C T_{\mathrm{MIN}}$ was independent of the initial $F_{\mathrm{V}} / F_{\mathrm{M}}$ of leaves. The $C T_{\mathrm{MAX}}$ of leaves with a wet paper surface did not differ significantly from dry ones both among and within species (all $p>0.2$; Table 1, S3, Fig. $2 b$ ), although the three species had different $C T_{\mathrm{MAX}}$ estimates. Leaves with higher $F_{\mathrm{V}} / F_{\mathrm{M}}$ had higher $C T_{\mathrm{MAX}}$ for $W$. ceracea.

\section{Surface wetness $\times$ heating/cooling rate experiment: effects on $C_{M I N}$ and NT}

$C T_{\mathrm{MIN}}$ of leaves of all species was higher on a wet surface and generally lower at faster cooling rates compared to leaves on a dry surface at slower cooling rate (Table S4). However, the interaction between surface wetness and cooling rate never had a significant effect on $C T_{\mathrm{MIN}}$; leaves on a wet surface had a consistently higher $C T_{\mathrm{MIN}}$ than those on a dry surface at both 15 and $60^{\circ} \mathrm{C} \mathrm{h}^{-1}$. A small subset of 17 leaves could be used to test whether surface wetness and 
309 cooling rates affected NT, however, due to this low sample size, we opted not to formally

310 analyse these data, but present descriptive findings in Fig. S2. NT of leaves measured on a wet

311 surface occurred at higher temperatures (around $-7^{\circ} \mathrm{C}$ ) independently of cooling rate, however

$312 N T$ occurred at lower temperatures on leaves on a dry surface, and perhaps slightly lower on

313 leaves exposed to a faster cooling rate (Fig. S2). NT generally occurred at temperatures $2-4^{\circ} \mathrm{C}$

314 higher than $C T_{\mathrm{MIN}}$, and the mean difference between $C T_{\mathrm{MIN}}$ and $N T$ was $1^{\circ} \mathrm{C}$ lower on a wet

315 surface compared to a dry surface (Fig. S2).

Heating/cooling rate experiment: effect of heating/cooling rate on $C T_{M A X}$ and $C T_{M I N}$

318 Varying heating/cooling rate affected the estimate of $T_{\text {crit }}$ for $C T_{\mathrm{MIN}}$ and $C T_{\mathrm{MAX}}$ considerably, 319 however each species responded differently. For $C T_{\mathrm{MIN}}$, slow cooling rates $\left(<10^{\circ} \mathrm{C} \mathrm{h}^{-1}\right)$ are 320 standard practice and here we used $3^{\circ} \mathrm{C} \mathrm{h}^{-1}$ as the reference category. We found no significant 321 differences between $3,6,15$, or $30^{\circ} \mathrm{C} \mathrm{h}^{-1}$ cooling rates overall, but when the plate was cooled at 322 faster rates, the $C T_{\mathrm{MIN}}$ values became very different to the slower cooling rates. At 60 and $323240^{\circ} \mathrm{C} \mathrm{h}^{-1} C T_{\mathrm{MIN}}$ was significantly lower relative to $3^{\circ} \mathrm{C} \mathrm{h}^{-1}$ for $M$. citrina and E. rubra (Table 2, 324 S5). For M. citrina, the values shifted depending on cooling rate, but with no clear pattern (Fig.

$3253 a$ ). In contrast, E. rubra had stable $C T_{\mathrm{MIN}}$ values for 3,6 , and $15^{\circ} \mathrm{C} \mathrm{h}^{-1}$ and more negative 326 values as cooling rate increased to 30,60 , and $240^{\circ} \mathrm{C} \mathrm{h}^{-1}$ (Table 2, S5, Fig. $3 a$ ). $C T_{\text {MIN }}$ for $W$.

327 ceracea was similar across most cooling rates and was only significantly different from when

328 the cooling rate was $30^{\circ} \mathrm{C} \mathrm{h}^{-1}$ (Table 2, S5). Variation in $C T_{\text {MIN }}$ was independent of the initial $329 \quad F_{\mathrm{V}} / F_{\mathrm{M}}$ of leaves.

$330 C T_{\text {MAX }}$ is typically measured with a heating rate of $60^{\circ} \mathrm{C} \mathrm{h}^{-1}$, so this was used as a 331 reference against which all other heating rates were compared. $C T_{\mathrm{MAX}}$ was highly dependent on

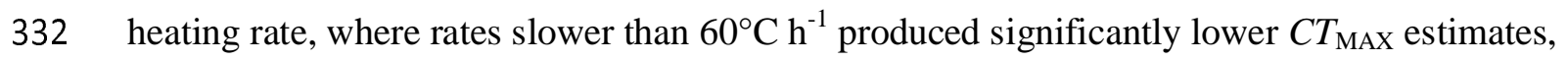
333 except for $6^{\circ} \mathrm{C} \mathrm{h}^{-1}$. Heating rates higher than $60^{\circ} \mathrm{C} \mathrm{h}^{-1}$ resulted in higher $C T_{\text {MAX }}$ estimates, 334 significantly so for $240^{\circ} \mathrm{C} \mathrm{h}^{-1}$ but not $120^{\circ} \mathrm{C} \mathrm{h}^{-1}$ (Table 2, S6). However, stark species-specific 335 responses were evident. $C T_{\text {MAX }}$ in $M$. citrina was very low at heating rates of 6 and $15^{\circ} \mathrm{C} \mathrm{h}^{-1}$ and 336 increased significantly and consistently with faster heating rates: only 45 and $60^{\circ} \mathrm{C} \mathrm{h}^{-1}$ yielded 337 similar $C T_{\text {MAX }}$ values (Table 2, S6, Fig. 3b). In contrast, $C T_{\text {MAX }}$ in E. rubra was higher at the 338 slowest rate (although the effect was marginal) compared to $60^{\circ} \mathrm{C} \mathrm{h}^{-1}$ but significantly lower at 33930 and $45^{\circ} \mathrm{C} \mathrm{h}^{-1}$ and not different from 120 and $240^{\circ} \mathrm{Ch} \mathrm{h}^{-1}$ (Table 2, S6, Fig. 3b). Similarly, $340 W$. ceracea had significantly higher $C T_{\text {MAX }}$ values at $6^{\circ} \mathrm{C} \mathrm{h}^{-1}$, but also at 120 and $240^{\circ} \mathrm{C} \mathrm{h}^{-1}$.

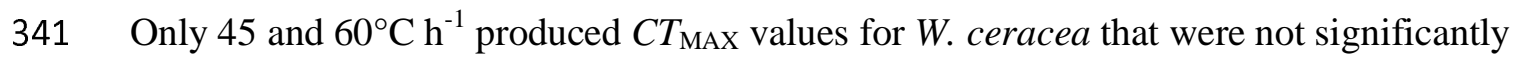


342 different (Table 2, S6, Fig. $3 b$ ). In all analyses except $E$. rubra individually, $F_{\mathrm{V}} / F_{\mathrm{M}}$ had a

343 significant positive relationship with $C T_{\mathrm{MAX}}$.

Heating/cooling rate experiment: predicted thermal limits as a function of heating/cooling

346 rate

347 We then modelled predicted $C T_{\mathrm{MAX}}$ and $C T_{\mathrm{MIN}}$ values against heating/cooling rate as a

348 continuous variable using a quadratic function to visualise the interspecific differences in

349 response to different heating/cooling rates when measuring thermal limits (Fig. 4a, b). The

350 difference between 60 and $240^{\circ} \mathrm{C} \mathrm{h}^{-1}$ introduced extreme uncertainty in the predicted $C T_{\text {MIN }}$ for

351 M. citrina, so the $240^{\circ} \mathrm{C} \mathrm{h}^{-1}$ rate was removed from the visualisation. The shape of each species'

$352 C T_{\mathrm{MAX}}$ and $C T_{\mathrm{MIN}}$ response to heating/cooling rate were clearly distinct from one another and

353 only $E$. rubra had a relatively stable predicted $C T_{\text {MAX }}$ value across all measured heating/cooling

354 rates. The variance tends to increase with faster heating/cooling rates for $C T_{\mathrm{MIN}}$, but the pattern

355 is less clear for $C T_{\text {MAX. }}$

\section{Discussion}

358 We sought to develop a reliable, high-throughput method for assessing thermal tolerance limits

359 of the photosynthetic apparatus. Many methods are used for measuring plant thermal tolerance

360 limits, but such variation has potential consequences for generating reasonable interpretations

361 and interspecific comparisons. Often, the rationale behind a published method is unclear and the

362 impacts of small methodological differences are difficult to assess (Geange et al. 2021). To

363 address this, we have demonstrated a method for measuring both cold and heat tolerance limits

364 of leaves using a thermoelectric plate and chlorophyll imaging fluorescence. In line with

365 previous applications of this technique, we provide evidence for the effects of controllable

366 experimental variables on estimates of $C T_{\mathrm{MIN}}$ and $C T_{\mathrm{MAX}}$. We quantify the significant effects of

367 measurement conditions and show that using a wet $v s$ dry surface for measuring $C T_{\mathrm{MIN}}$ and that

368 variation in heating/cooling rates leads to substantial differences in $C T_{\text {MIN }}$ and $C T_{\text {MAX }}$. We

369 aimed to develop a practical method that maximises informative value and minimises

370 experimental noise among samples. In the case of heating/cooling rate, there is high species

371 specificity. Below we outline potential mechanistic explanations for our findings along with

372 testable hypotheses, and then propose best practices for measuring the thermal tolerance limits

373 of leaves. 


\section{Pros and cons of the T-F 0 Peltier plate-Maxi-Imaging fluorimeter method}

377 Measuring the temperature-dependent change in basal chlorophyll fluorescence is one of several

378 potential methods that researchers can use to quantify the critical thermal limits of

379 photosynthesis activation and photosynthetic apparatus stability (Ilík et al. 2003). The method

380 that we present here offers improvements over earlier and alternative versions that use bulky

381 water baths or freezing chambers, or smaller capacity Peltier plates (e.g., Schreiber and Berry

382 1977; Braun et al. 2002; Knight and Ackerly 2002; Neuner and Pramsohler 2006), and adds

383 several key features. The Peltier plate-Maxi-Imaging fluorimeter system is relatively compact

384 and transportable for field applications when provided with a continuous power source. It offers

385 precise temperature control $\left( \pm 0.1^{\circ} \mathrm{C}\right.$ precision and $\pm 1{ }^{\circ} \mathrm{C}$ tolerance $)$ and high versatility by

386 being programmable for both cooling and heating rapidly at set rates. It can be programmed for

387 stepwise temperature treatments or non-linear temperature programs, or temperature shock

388 treatments depending on the desired application. Furthermore, the $T-F_{0}$ curve allows for the

389 calculation of other parameters (e.g., Knight and Ackerly 2002), including the temperatures at

$39050 \%$ or $100 \%$ of relative $F_{0}\left(T_{50}\right.$ and $T_{\max }$, respectively) and ice nucleation temperatures (NT) for

391 cold tolerance assays if each leaf sample has a thermocouple attached to it (e.g., Briceño et al.

392 2014). When using detached leaves or leaf discs, the potential throughput of the system is

393 substantial (Fig. S1). The $120 \times 90 \mathrm{~mm}$ optimal imaging area on the Peltier plate can fit $>100$

394 leaf discs or small leaf samples up to $1 \mathrm{~cm}^{2}$ or $>30$ samples that are up to $2 \mathrm{~cm}^{2}$ each, thus

395 throughput is mostly constrained by sampling and setting up that many leaves.

396 As with any laboratory equipment, there are limitations to the Peltier plate-Maxi-

397 Imaging fluorimeter system. Unlike freezing chambers, this system does not allow for whole-

398 plant measurements. There is some software modification required for controlling the

399 heating/cooling rates using the Peltier plate system, although newer temperature controllers and

400 software revisions than those used here are now available. The Peltier plate-Maxi-Imaging

401 fluorimeter system is a versatile phenotyping tool for thermal tolerance, ecophysiology, and

402 photosynthesis research. Below, we discuss the results of testing the system with wet and dry

403 filter paper as surfaces and the effects of heating/cooling rates.

404

405 A dry surface avoids experimental artefacts

406 Using wet filter paper as a surface for the leaf samples significantly reduced the apparent

407 measured $C T_{\mathrm{MIN}}$ but had no effect on $C T_{\mathrm{MAX}}$. Wet filter paper was initially tested to attempt to

408 avoid leaf dehydration by providing a saturating atmosphere, preventing leaf evapotranspiration.

409 In our cold tolerance assay, freezing of the water in the wet filter paper most likely began 
410 propagating ice from outside the leaf into the apoplastic space, thereby freezing the apoplast in

411 the leaf tissue at higher temperatures than leaves on the dry surface. When radiative frost occurs,

412 air humidity condenses on the leaf surface, resulting in a wet leaf surface that may induce

413 heterogenous extrinsic nucleation in natural frosts (Pearce 2001). Thus, the wet filter paper

414 surface acted as an extrinsic ice nucleator and likely prevented the leaves from supercooling

415 (Sakai and Larcher 1987; Pearce 2001; Larcher 2003). Our exploratory tests between wet and

416 dry surfaces at different cooling rates demonstrated that on a dry filter paper surface, leaves

417 appeared to supercool $2-4{ }^{\circ} \mathrm{C}$ below those leaves on a wet surface. $N T$ occurred earlier and at

418 temperatures closer to $C T_{\mathrm{MIN}}$ on the wet surface and was more variable in comparison to leaves

419 on a dry surface. Although this supercooling phenomenon requires further targeted investigation

420 in future, our initial tests suggest that a wet surface induces earlier ice formation and

421 propagation at warmer temperatures and hence reduces leaf supercooling capacity, and that

422 supercooling capacity might be exacerbated by faster cooling rates.

423 The initial water status of leaf samples is still crucial, as water-stressed leaves can have

424 compromised (Verslues et al. 2006) or even enhanced stress tolerance (Havaux 1992).

425 Therefore, we recommend that detached leaves should be transported in a manner that maintains

426 leaf water content after sampling (e.g., sealing leaves with plastic film wrap, using damp paper

427 towel, or cut stems placed in water) so that leaves are either maintained at collection conditions

428 or fully hydrated at the start of the thermal tolerance assay.

429

430 Maximising throughput without compromising results

431 A wide range of heating/cooling rates have been used in previous studies of thermal limits to

432 photosynthesis (Table S1). We have demonstrated that heating/cooling rate strongly influences

433 both $C T_{\mathrm{MIN}}$ and $C T_{\mathrm{MAX}}$ values with varying magnitude and complex patterns for different

434 species. Indeed, we saw such strong species-specific responses to different heating/cooling rates

435 (particularly for heat) that if one were to measure the $C T_{\mathrm{MAX}}$ for three species measured at the

436 same heating rate of $45^{\circ} \mathrm{C} \mathrm{h}^{-1}$, they would conclude that all the species have identical heat

437 threshold temperatures, yet the same experiment conducted with a heating rate of $6^{\circ} \mathrm{C} \mathrm{h}^{-1}$ and

$438240^{\circ} \mathrm{C} \mathrm{h}^{-1}$ would result in entirely different, and opposing, conclusions. For comparative studies

439 that measure species with different leaf morphology, physiology, and biochemical constituents,

440 it is crucial that we clarify and refine what physiological event(s) we aim to characterise with

441 the $T-F_{0}$ approach. From a practical standpoint, our aim was to identify the fastest

442 heating/cooling rates that would allow repeatable, interpretable measures of $T_{\text {crit }}$. 
443

444

445

446

447

448

449

450

451

452

453

454

455

456

457

458

459

460

461

462

463

464

465

466

467

468

469

470

471

472

473

474

475

Heating rates will determine the potential for activation and extent of the upregulation of physiological processes and protective mechanisms within the leaf when approaching thermal extremes (Bilger et al. 1984; Frolec et al. 2008). The rise in $F_{0}$ during a measure of $C T_{\mathrm{MAX}}$ indicates when photosynthetic activity is markedly reduced and thereafter the thylakoid membrane is disrupted (Havaux et al. 1988; Nauš et al. 1992). If leaf samples are heated only up to the temperature of the initial rise in $F_{0}, C T_{\mathrm{MAX}}$, and then cooled, it is possible that membrane disruption can be reversed (Yamane et al. 1997; Frolec et al. 2008). However, irreversible damage to PSII through physiological changes to the photosynthetic apparatus and then physical membrane separation (i.e., denaturation) is correlated with the continued rapid rise and maxima of $F_{0}$ with sustained extreme temperatures (Terzaghi et al. 1989; Frolec et al. 2008).

Specifically, the first peak in $F_{0}$ shortly after $C T_{\mathrm{MAX}}$ and between $40-50^{\circ} \mathrm{C}$ is due to irreversible inactivation of PSII and the secondary $F_{0}$ peak between $55-60^{\circ} \mathrm{C}$ originates from the denaturing of chlorophyll-containing protein complexes (Ilík et al. 2003). Leaves can reduce the photochemical and oxidative impairment induced by heat stress by thermal dissipation of excessive excitation energy to maintain PSII in an oxidative state, and by upregulating heat shock proteins and antioxidant activity (Allakhverdiev et al. 2008; Silva et al. 2010). Changes to the lipid composition of the thylakoid membrane reduces the fluidity of the membrane thereby being more stable at high temperatures (Allakhverdiev et al. 2008). The upregulation of these protective mechanisms of PSII can occur relatively quickly, sometimes $<1 \mathrm{~h}$ of heat stress (Havaux 1993), thus how protected the leaf is against PSII inactivation will depend on the heating rate.

For cold tolerance assays, cooling rates likely modify the dynamic and primary site of ice nucleation. Intrinsic ice nucleation may lead to ice formation in the xylem (Hacker and Neuner 2007), while extrinsic nucleation occurs at the leaf epidermis (Pearce and Ashworth 1992). Rates of cooling may also influence supercooling capacity; usually faster cooling (within the range of this study) increases supercooling capacity (Gokhale 1965). Despite most freezing studies using cooling rates that are more reminiscent of natural freezing rates $\left(\leq 5^{\circ} \mathrm{C} \mathrm{h}^{-1}\right)$, we did not find a clear difference among $C T_{\mathrm{MIN}}$ values at cooling rates of 3,6 , and $15^{\circ} \mathrm{C} \mathrm{h}^{-1}$. We hypothesise that reducing the temperature relatively slowly (e.g., $\leq 15^{\circ} \mathrm{C} \mathrm{h}^{-1}$ ) could allow the cell to adjust osmotically and partially counterbalance the reduced water potential of the frozen apoplast restricting cell dehydration, which would be avoided at faster cooling speeds. Thus, the consideration for the freezing tolerance cooling rates becomes a question of what is the greatest cooling rate that allows more realistic osmotic adjustments within the leaf. 
For W. ceracea and E. rubra, increasing temperature slowly $\left(<30^{\circ} \mathrm{C} \mathrm{h}^{-1}\right)$ appears to

477

478

479

480

481

482

483

484

485

486

487

488

489

490

491

492

493

494

495

496

497

498

499

500

501

502

503

504

505

506

507

508

509

allow time for induction of protective mechanisms such that slower heating rates result in higher $C T_{\text {MAX }}$ values. Conversely, changing temperature more quickly $\left(30-60^{\circ} \mathrm{C} \mathrm{h}^{-1}\right)$ prevents membranes from inducing heat-hardening or for antioxidants to be upregulated and take effect, such that measured heat tolerance limits is relatively stable at these heating rates. Our results indicate that beyond a rate of $60^{\circ} \mathrm{C} \mathrm{h}^{-1}$, the increase in $F_{0}$ occurs more slowly than the temperature increase and the temperature of the leaf samples (as measured by thermocouples) also lags significantly behind the temperature of the Peltier plate, thus the $C T_{\mathrm{MAX}}$ may be overestimated (Fig. 3b). Hence, using the thermistor (plate) temperature will overestimate the temperature of the leaf, and therefore, its tolerance limit. Furthermore, the faster that the plate temperature is changed, the more potential variation among leaf temperatures. We acknowledge that the method could be improved by using individual thermocouples for each leaf sample, particularly for cold tolerance to measure ice nucleation temperature $(N T)$, however, we have verified that there is minimal variation $\left( \pm 1^{\circ} \mathrm{C}\right)$ across the Peltier plate surface.

The species specificity of the heating rate dependence of $C T_{\mathrm{MAX}}$ was striking, particularly in the case of $M$. citrina. A slow heating rate of $6^{\circ} \mathrm{C} \mathrm{h}^{-1}$ results in a very low estimate for $C T_{\mathrm{MAX}}$ of only $36^{\circ} \mathrm{C}$, which suggests that the heat tolerance of this species is poor, yet at heating rates $\geq 30^{\circ} \mathrm{C} \mathrm{h}^{-1}$, this species is apparently as or more heat tolerant than the other species. Slow heating rates mean that the leaves are slow to reach more stressful temperatures, but also that they are held at these temperatures for longer periods of time. We hypothesise that the lower heat tolerance limit at slow heating rates could be due to leaf water being tightly bound and preventing cooling via transpiration or the heated leaf oils being unable to volatilise, thereby destabilising membranes and effectively 'slow-cooking' the leaf. For this species, the higher heating rates are therefore likely more indicative of photosynthetic thermal tolerance limits.

The $T-F_{0}$ method is a rapid measurement compared to other $F_{\mathrm{V}} / F_{\mathrm{M}}$-based assessments of thermal tolerance. Determining the temperature at which $50 \%$ of the potential thermal damage (lethal temperature) to the plant tissue occurs $\left(L T_{50}\right)$ is a common but very time-consuming technique that also requires more plant material. Different individual leaves are heated/cooled to and held at set temperatures for 1-3 h, and then $F_{\mathrm{V}} / F_{\mathrm{M}}$ is measured over 1-24 h post-thermal exposure to determine the point of irreversible damage. We note that $F_{0}$ can be affected by leaf properties including the efficiency of PSII, the leaf chlorophyll content and ratios, and leaf thickness, which may affect thermal tolerance estimates more than those measured using $F_{\mathrm{V}} / F_{\mathrm{M}}$. Therefore, to better understand what occurs within a leaf during exposure to thermal extremes, it 
510 would be valuable to characterise the $T-F_{0}$ curve and identify the $C T_{\text {MIN }}$ and $C T_{\text {MAX }}$ values for a

511 plant. One could then heat/cool and hold leaf samples at these threshold temperatures for a set

512 time, then measure $F_{\mathrm{V}} / F_{\mathrm{M}}$ with the same Maxi-Imaging fluorescence system to examine

513 potential recovery from exposure to damaging temperatures (e.g., Buchner et al. 2015). Then,

514 one could investigate the correlation between $C T$ and $L T$ metrics and determine the extent and

515 reversibility of damage. A more complete micro-scale understanding of thermal tolerance

516 responses and species specificity would be enhanced by exploring tissue biochemistry, the

517 regulation of heat shock proteins, and gene expression at thermal extremes (Geange et al. 2021).

518 At the macro end of the scale, remote sensing tools allows landscape scale estimations of

519 photosynthetic tolerance to heating using the Photochemical Reflectance Index (PRI), which

520 strongly relates to stress changes in photosynthetic machinery (Sukhova and Sukhov 2018;

521 Yudina et al. 2020). Comparative studies on the accuracy and precision of different micro- and

522 macro-scale techniques for estimating thermal tolerance of plants will be necessary for

523 maximising agricultural and ecological monitoring efforts.

\section{Towards standardised approaches for comparative thermal tolerance research}

526 There will never be a perfect one-size-fits-all method for comparative measures of plant

527 photosynthetic thermal tolerance, but our exploration of method variation we find there is a

528 reasonable set of conditions that will fit most. We advocate that researchers use well-hydrated

529 leaves (unless hydration status is an element of their experiment) and dry surface for these

530 measures. Doing so allows easy comparison across experiments and gives a more indicative

531 measure of the lowest potential $C T_{\mathrm{MIN}}$.

532 We sought the maximum heating/cooling rate that was repeatable and reliable. Our

533 results suggest that there is a point beyond which temperatures are changed too quickly and the

$534 T_{\text {crit }}$ value is exaggerated due to the change in $F_{0}$ lagging the change in leaf temperature,

535 especially in heat tolerance limit assays. For an experiment on a single or few species, pilot

536 studies on the effects of heating/cooling rates are advisable. For broad interspecific studies,

537 particularly in natural systems where other variables such as thermal history and the

538 environment cannot be controlled, using a common rate for heating and for cooling is the only

539 feasible approach. For such comparative work, we recommend a heating rate of not less than

$54030^{\circ} \mathrm{C} \mathrm{h}^{-1}$ (up to $60^{\circ} \mathrm{C} \mathrm{h}^{-1}$ to avoid any potential heat hardening) for $C T_{\mathrm{MAX}}$ and a cooling rate at

541 or below $15^{\circ} \mathrm{C} \mathrm{h}^{-1}$ for $C T_{\mathrm{MIN}}$. We recognise that this is a slower heating rate than often used for

$542 C T_{\mathrm{MAX}}$ and a faster than usual cooling rate for $C T_{\mathrm{MIN}}$. However, we found that the $15^{\circ} \mathrm{C} \mathrm{h}^{-1}$ rate

543 was not significantly different to slower rates for $C T_{\mathrm{MIN}}$ and thus represents the most efficient 
544 rate that could yield results reflective of natural scenarios. For $C T_{\mathrm{MAX}}$, we argue that the 30

$54560^{\circ} \mathrm{C} \mathrm{h}^{-1}$ rates enable physiological mechanisms that would normally provide some thermal

546 protection to the photosystem and cell membranes to be induced, without lag exaggerating

$547 C T_{\mathrm{MAX}}$, and may therefore be a more realistic or relevant measurement of thermal tolerance than

548 that provided by faster rates. These rates remain practical for achieving high throughput,

549 especially with sample sizes that can be accommodated by large Peltier plates combined with

550 the multi-sample imaging of Maxi-Imaging fluorimeters.

551 Clearly, any experimental thermal tolerance assay cannot perfectly mirror the conditions

552 of a natural extreme thermal event. Rates of heating and cooling of plant tissues in nature are

553 non-linear, not sustained, and strongly mediated by external conditions such as wind, solar

554 radiation, season, and elevation (Sakai and Larcher 1987; Leuning and Cremer 1988; Vogel

555 2009). The researcher must always remain appreciative of how extrinsic factors could affect

556 these values and interpretations thereof for their study system. However, $T-F_{0}$ curves and

557 derived $T_{\text {crit }}$ values can indicate what the potential thermal limits of leaves are, under absolute

558 conditions. The method provides power for comparative research, and also ample opportunity to

559 explore the underlying mechanisms of species level differentiation. Moving toward a deeper

560 understanding of the physiological processes conferring thermal tolerance is crucial in the

561 changing climate where extreme weather events are increasing in frequency and intensity

562 (Buckley and Huey 2016; Harris et al. 2018).

\section{Conclusions}

565 The Peltier plate-Maxi-Imaging fluorimeter system described and tested here allows relatively

566 high-throughput measurement of $T-F_{0}$ and the critical thermal limits to inactivation of

567 photosynthesis. This system offers great flexibility and substantially expands on previous

568 versions. We have demonstrated that use of wet $v s$ dry surface can significantly affect the $C T_{\text {MIN }}$

569 estimate, but not $C T_{\mathrm{MAX}}$, and that heating/cooling rates have strong species-specific effects on

570 both $C T_{\mathrm{MIN}}$ and $C T_{\mathrm{MAX}}$. Awareness of the physiological processes that underlie the rapid rise in

$571 \quad F_{0}$ and consideration of interspecific differences in leaf physiology and biochemistry are

572 essential for making effective choices in the rate of heating or cooling leaf samples. We

573 recommend the use of parameters that maximise repeatability and efficiency of the

574 measurements without introducing artefacts of heating/cooling rate. As plants around the world

575 are exposed to more thermal extremes by the effects of climate change, versatile

576 ecophysiological tools such as this Peltier plate-Maxi-Imaging fluorimeter system will be

577 valuable for generating new insights in plant responses and thermal tolerance limits. 


\section{Conflicts of Interest}

579 The authors declare no conflicts of interest.

\section{Acknowledgements}

582 We sincerely thank Ya Zhang for modifying the LabVIEW software for heating/cooling rate

583 control, ANU plant services staff for maintaining glasshouse plants, and Jack Egerton and ANU

584 workshop staff for technical support. We thank three anonymous reviewers and Loeske Kruuk

585 for their constructive feedback on earlier versions of this manuscript. This research was

586 supported by the Australian Research Council (DP170101681).

\section{Author contribution statement}

589 PAA, KMG, AAC, and ABN designed the experiments. PAA, KMG, AAC performed the

590 experiments and collected the data. PAA curated the data and performed the data analyses and

591 visualisation. PAA, VFB, LAB, and ABN interpreted the results and wrote the manuscript with

592 input from all authors.

593

\section{Supplemental material}

595 The following supplemental materials are available.

596 Supplemental Table S1: Samples of heating/cooling rate variation from the literature.

597 Supplemental Table S2: Mean values for $C T_{\mathrm{MIN}}, C T_{\mathrm{MAX}}$, and $F_{\mathrm{V}} / F_{\mathrm{M}}$ for each species and

598 experimental condition.

599 Supplemental Table S3: Full statistical reporting for effects of wet $v s$ dry surface for $C T_{\mathrm{MIN}}$

600 and $C T_{\text {MAX. }}$

601 Supplemental Table S4: Full statistical reporting for effects of wet $v s$ dry surface combined 602 with heating/cooling rate on $C T_{\mathrm{MIN}}$.

603 Supplemental Table S5: Full statistical reporting for effects of heating/cooling rate for $C T_{\text {MIN }}$.

604 Supplemental Table S6: Full statistical reporting for effects of heating/cooling rate for $C T_{\text {MAX. }}$.

605 Supplemental Figure S1: Various experimental applications of the Peltier plate and

606 chlorophyll fluorescence Maxi-Imaging-PAM system.

607 Supplemental Figure S2: Effects of wet $v s$ dry surface combined with cooling rate on $C T_{\text {MIN }}$ 608 and NT. 


\section{References}

610 Allakhverdiev, SI, Kreslavski, VD, Klimov, VV, Los, DA, Carpentier, R, Mohanty, P (2008)

611 Heat stress: an overview of molecular responses in photosynthesis. Photosynthesis Research 98, 541-550.

Baker, NR (2008) Chlorophyll fluorescence: a probe of photosynthesis in vivo. Annual Review of Plant Biology 59, 89-113.

Berry, J, Björkman, O (1980) Photosynthetic response and adaptation to temperature in higher plants. Annual Review of Plant Physiology 31, 491-543.

Bilger, H-W, Schreiber, U, Lange, OL (1984) Determination of leaf heat resistance: comparative investigation of chlorophyll fluorescence changes and tissue necrosis methods. Oecologia 63, 256-262.

Bita, CE, Gerats, T (2013) Plant tolerance to high temperature in a changing environment: scientific fundamentals and production of heat stress-tolerant crops. Frontiers in Plant Science 4, 273.

Braun, V, Buchner, O, Neuner, G (2002) Thermotolerance of photosystem 2 of three alpine plant species under field conditions. Photosynthetica 40, 587-595.

Briantais, J-M, Dacosta, J, Goulas, Y, Ducruet, J-M, Moya, I (1996) Heat stress induces in leaves an increase of the minimum level of chlorophyll fluorescence, $\mathrm{F}_{\mathrm{o}}$ : A timeresolved analysis. Photosynthesis Research 48, 189-196.

Briceño, VF, Harris-Pascal, D, Nicotra, AB, Williams, E, Ball, MC (2014) Variation in snow cover drives differences in frost resistance in seedlings of the alpine herb Aciphylla glacialis. Environmental and Experimental Botany 106, 174-181.

Buchner, O, Neuner, G (2009) A low-temperature freezing system to study the effects of temperatures to $-70{ }^{\circ} \mathrm{C}$ on trees in situ. Tree Physiology 29, 313-320. situ demonstrates a protective role of irradiation on photosynthetic performance in alpine plants. Plant, Cell \& Environment 38, 812-826. 
636 Buckley, LB, Huey, RB (2016) How extreme temperatures impact organisms and the evolution of their thermal tolerance. Integrative and Comparative Biology 56, 98-109.

638 Frolec, J, Ilík, P, Krchňák, P, Sušila, P, Nauš, J (2008) Irreversible changes in barley leaf 639 chlorophyll fluorescence detected by the fluorescence temperature curve in a linear 640 heating/cooling regime. Photosynthetica 46, 537-546.

641 Geange, SR, Arnold, PA, Catling, AA, Coast, O, Cook, AM, Gowland, KM, Leigh, A, 642 Notarnicola, RF, Posch, BC, Venn, SE, Zhu, L, Nicotra, AB (2021) The thermal 643 tolerance of photosynthetic tissues: a global systematic review and agenda for future $644 \quad$ research. New Phytologist 10.1111/nph.17052.

645 Goh, C-H, Ko, S-M, Koh, S, Kim, Y-J, Bae, H-J (2012) Photosynthesis and environments: 646 photoinhibition and repair mechanisms in plants. Journal of Plant Biology 55, 93-101.

647 Gokhale, NR (1965) Dependence of freezing temperature of supercooled water drops on rate of 648 cooling. Journal of the Atmospheric Sciences 22, 212-216.

649 Goraya, GK, Kaur, B, Asthir, B, Bala, S, Kaur, G, Farooq, M (2017) Rapid injuries of high 650 temperature in plants. Journal of Plant Biology 60, 298-305.

651 Hacker, J, Neuner, G (2007) Ice propagation in plants visualized at the tissue level by infrared 652 differential thermal analysis (IDTA). Tree Physiology 27, 1661-1670.

653 Harrell, FEJ (2019) 'Hmisc: Harrell Miscellaneous.' https://CRAN.R$654 \quad$ project.org $/$ package=Hmisc)

655 Harris, RMB, Beaumont, LJ, Vance, TR, Tozer, CR, Remenyi, TA, Perkins-Kirkpatrick, SE, 656 Mitchell, PJ, Nicotra, AB, McGregor, S, Andrew, NR, Letnic, M, Kearney, MR, Wernberg, T, Hutley, LB, Chambers, LE, Fletcher, MS, Keatley, MR, Woodward, CA, Williamson, G, Duke, NC, Bowman, DMJS (2018) Biological responses to the press and pulse of climate trends and extreme events. Nature Climate Change 8, 579-587.

660 Havaux, M (1992) Stress tolerance of photosystem II in vivo. Plant Physiology 100, 424-432.

661 Havaux, M (1993) Rapid photosynthetic adaptation to heat stress triggered in potato leaves by 662 moderately elevated temperatures. Plant, Cell \& Environment 16, 461-467. 
663

664

665

666

667

668

669

670

671

672

673

674

675

676

677

678

679

680

681

682

683

684

685

686

687

688

689

690

691

Havaux, M, Ernez, M, Lannoye, R (1988) Correlation between heat tolerance and drought tolerance in cereals demonstrated by rapid chlorophyll fluorescence tests. Journal of Plant Physiology 133, 555-560.

Hüve, K, Bichele, I, Tobias, M, Niinemets, Ü (2006) Heat sensitivity of photosynthetic electron transport varies during the day due to changes in sugars and osmotic potential. Plant, Cell \& Environment 29, 212-228.

Ilík, P, Kouřil, R, Kruk, J, Myśliwa-Kurdziel, B, Popelková, H, Strzałka, K, Nauš, J (2003) Origin of chlorophyll fluorescence in plants at $55-75^{\circ} \mathrm{C}$. Photochemistry and Photobiology 77, 68-76.

IPCC (2018) Global Warming of $1.5^{\circ} \mathrm{C}$ : An IPCC Special Report on the Impacts of Global Warming of $1.5^{\circ} \mathrm{C}$ Above Pre-industrial Levels and Related Global Greenhouse Gas Emission Pathways, in the Context of Strengthening the Global Response to the Threat of Climate Change, Sustainable Development, and Efforts to Eradicate Poverty. Geneva, Switzerland. Available at https://www.ipcc.ch/sr15/.

Janion-Scheepers, C, Phillips, L, Sgrò, CM, Duffy, GA, Hallas, R, Chown, SL (2018) Basal resistance enhances warming tolerance of alien over indigenous species across latitude. Proceedings of the National Academy of Sciences 115, 145-150.

Knight, CA, Ackerly, DD (2002) An ecological and evolutionary analysis of photosynthetic thermotolerance using the temperature-dependent increase in fluorescence. Oecologia 130, 505-514.

Larcher, W (2003) 'Physiological plant ecology: ecophysiology and stress physiology of functional group.' (Springer-Verlag: Berlin, Germany)

Leigh, A, Sevanto, S, Ball, MC, Close, JD, Ellsworth, DS, Knight, CA, Nicotra, AB, Vogel, S (2012) Do thick leaves avoid thermal damage in critically low wind speeds? New Phytologist 194, 477-487.

Leuning, R, Cremer, KW (1988) Leaf temperatures during radiation frost Part I. Observations. Agricultural and Forest Meteorology 42, 121-133.

Logan, BA, Adams, WW, Demmig-Adams, B (2007) Avoiding common pitfalls of chlorophyll fluorescence analysis under field conditions. Functional Plant Biology 34, 853-859. 
692 Mathur, S, Agrawal, D, Jajoo, A (2014) Photosynthesis: response to high temperature stress. Journal of Photochemistry and Photobiology B: Biology 137, 116-126.

Muggeo, VMR (2017) Interval estimation for the breakpoint in segmented regression: a smoothed score-based approach. Australian \& New Zealand Journal of Statistics 59, 311-322.

Murchie, EH, Lawson, T (2013) Chlorophyll fluorescence analysis: a guide to good practice and understanding some new applications. Journal of Experimental Botany 64, 3983-3998.

Nauš, J, Kuropatwa, R, Klinkovskÿ, T, Ilík, P, Lattová, J, Pavlová, Z (1992) Heat injury of barley leaves detected by the chlorophyll fluorescence temperature curve. Biochimica et Biophysica Acta (BBA) - Bioenergetics 1101, 359-362.

Neuner, G, Pramsohler, M (2006) Freezing and high temperature thresholds of photosystem 2 compared to ice nucleation, frost and heat damage in evergreen subalpine plants. Physiologia Plantarum 126, 196-204.

O'Sullivan, OS, Heskel, MA, Reich, PB, Tjoelker, MG, Weerasinghe, LK, Penillard, A, Zhu, L, Egerton, JJG, Bloomfield, KJ, Creek, D, Bahar, NHA, Griffin, KL, Hurry, V, Meir, P, Turnbull, MH, Atkin, OK (2017) Thermal limits of leaf metabolism across biomes.

O'Sullivan, OS, Weerasinghe, KWLK, Evans, JR, Egerton, JJG, Tjoelker, MG, Atkin, OK Global Change Biology 23, 209-223.

713 Pearce, RS (2001) Plant freezing and damage. Annals of Botany 87, 417-424.

714 Pearce, RS, Ashworth, EN (1992) Cell shape and localisation of ice in leaves of overwintering 715 wheat during frost stress in the field. Planta 188, 324-331.

716 Potvin, C (1985) Effect of leaf detachment on chlorophyll fluorescence during chilling experiments. Plant Physiology 78, 883-886.

718 R Core Team (2020) 'R: A language and environment for statistical computing.' (R Foundation 719 for Statistical Computing: Vienna, Austria) 
720

721

722

723

724

725

726

727

728

729

730

731

732

733

734

735

736

737

738

739

740

741

742

743

744

745

746

747

748

Sakai, A, Larcher, W (1987) ' Frost survival of plants: responses and adaptation to freezing stress.' (Springer-Verlag: Berlin, Germany)

Schreiber, U, Berry, JA (1977) Heat-induced changes of chlorophyll fluorescence in intact leaves correlated with damage of the photosynthetic apparatus. Planta 136, 233-238.

Schreiber, U, Hormann, H, Neubauer, C, Klughammer, C (1995) Assessment of photosystem II photochemical quantum yield by chlorophyll fluorescence quenching analysis. Functional Plant Biology 22, 209-220.

Silva, EN, Ferreira-Silva, SL, Fontenele, AdV, Ribeiro, RV, Viégas, RA, Silveira, JAG (2010) Photosynthetic changes and protective mechanisms against oxidative damage subjected to isolated and combined drought and heat stresses in Jatropha curcas plants. Journal of Plant Physiology 167, 1157-1164.

Sinclair, BJ, Marshall, KE, Sewell, MA, Levesque, DL, Willett, CS, Slotsbo, S, Dong, Y, Harley, CDG, Marshall, DJ, Helmuth, BS, Huey, RB (2016) Can we predict ectotherm responses to climate change using thermal performance curves and body temperatures? Ecology Letters 19, 1372-1385.

Smillie, RM, Nott, R, Hetherington, SE, Öquist, G (1987) Chilling injury and recovery in detached and attached leaves measured by chlorophyll fluorescence. Physiologia Plantarum 69, 419-428.

Sukhov, V, Gaspirovich, V, Mysyagin, S, Vodeneev, V (2017) High-temperature tolerance of photosynthesis can be linked to local electrical responses in leaves of pea. Frontiers in Physiology 8, 763.

Sukhova, E, Sukhov, V (2018) Connection of the photochemical reflectance index (PRI) with the photosystem II quantum yield and nonphotochemical quenching can be dependent on variations of photosynthetic parameters among investigated plants: a meta-analysis. Remote Sensing 10, 771.

Sung, D-Y, Kaplan, F, Lee, K-J, Guy, CL (2003) Acquired tolerance to temperature extremes. Trends in Plant Science 8, 179-187.

Terzaghi, WB, Fork, DC, Berry, JA, Field, CB (1989) Low and high temperature limits to PSII. Plant Physiology 91, 1494-1500. 
749 Verslues, PE, Agarwal, M, Katiyar-Agarwal, S, Zhu, J, Zhu, J-K (2006) Methods and concepts

750 in quantifying resistance to drought, salt and freezing, abiotic stresses that affect plant

$751 \quad$ water status. The Plant Journal 45, 523-539.

752 Vogel, S (2009) Leaves in the lowest and highest winds: temperature, force and shape. New

753 Phytologist 183, 13-26.

754 Yamane, Y, Kashino, Y, Koike, H, Satoh, K (1997) Increases in the fluorescence $F_{0}$ level and

755 reversible inhibition of Photosystem II reaction center by high-temperature treatments in

756 higher plants. Photosynthesis Research 52, 57-64.

757 Yudina, L, Sukhova, E, Gromova, E, Nerush, V, Vodeneev, V, Sukhov, V (2020) A light-

758 induced decrease in the photochemical reflectance index (PRI) can be used to estimate

759 the energy-dependent component of non-photochemical quenching under heat stress and

760 soil drought in pea, wheat, and pumpkin. Photosynthesis Research 146, 175-187.

761 Zhu, L, Bloomfield, KJ, Hocart, CH, Egerton, JJG, O'Sullivan, OS, Penillard, A, Weerasinghe,

762 LK, Atkin, OK (2018) Plasticity of photosynthetic heat tolerance in plants adapted to

763 thermally contrasting biomes. Plant, Cell \& Environment 41, 1251-1262.

764 Zinn, KE, Tunc-Ozdemir, M, Harper, JF (2010) Temperature stress and plant sexual

765 reproduction: uncovering the weakest links. Journal of Experimental Botany 61, 1959-

7661968.

767

768 


\section{Tables}

770

771 Table 1. Summary of analyses of all species and species-specific effects of wet $v s$ dry filter

772 paper surface on $C T_{\mathrm{MIN}}$ and $C T_{\mathrm{MAX}}$.

\begin{tabular}{|c|c|c|c|c|}
\hline $\begin{array}{l}\text { Response: } C T_{\mathrm{MIN}} \\
\text { Fixed effects }\end{array}$ & $\begin{array}{c}\text { All species } \\
\text { Estimate }\end{array}$ & $\begin{array}{l}\text { W. ceracea } \\
\text { Estimate }\end{array}$ & $\begin{array}{c}\text { M. citrina } \\
\text { Estimate }\end{array}$ & $\begin{array}{c}\text { E. rubra } \\
\text { Estimate }\end{array}$ \\
\hline $\begin{array}{l}\text { Dry surface / E. rubra } \\
\text { (intercept) }\end{array}$ & $-18.36 *$ & $\begin{array}{l}\text { Intercept: } \\
\quad-5.71\end{array}$ & $\begin{array}{l}\text { Intercept: } \\
\text {-20.36* }\end{array}$ & $\begin{array}{l}\text { Intercept: } \\
\mathbf{- 3 1 . 2 6 * *}\end{array}$ \\
\hline Wet surface & $3.81 * * *$ & $3.92 * * *$ & $2.98 * *$ & $3.99 * * *$ \\
\hline$F_{\mathrm{V}} / F_{\mathrm{M}}$ & 6.19 & -9.89 & 4.72 & 23.54 \\
\hline M. citrina & $-3.50 * * *$ & -- & -- & -- \\
\hline W. ceracea & -0.42 & -- & -- & -- \\
\hline $\mathrm{R}^{2}$ & 0.464 & 0.288 & 0.374 & 0.527 \\
\hline $\begin{array}{l}\text { Response: } C T_{\mathrm{MAX}} \\
\text { Fixed effects }\end{array}$ & $\begin{array}{c}\text { All species } \\
\text { Estimate }\end{array}$ & $\begin{array}{c}\text { W. ceracea } \\
\text { Estimate }\end{array}$ & $\begin{array}{c}\text { M. citrina } \\
\text { Estimate }\end{array}$ & $\begin{array}{l}\text { Q.phellos } \\
\text { Estimate }\end{array}$ \\
\hline $\begin{array}{l}\text { Dry surface / } M \text {. citrina } \\
\text { (intercept) }\end{array}$ & $32.76 * * *$ & $\begin{array}{l}\text { Intercept: } \\
6.90\end{array}$ & $\begin{array}{l}\text { Intercept: } \\
\text { 36.31* }\end{array}$ & $\begin{array}{l}\text { Intercept: } \\
\mathbf{4 7 . 3 4 * * *}\end{array}$ \\
\hline Wet surface & -0.55 & -1.47 & 0.32 & -0.63 \\
\hline$F_{\mathrm{V}} / F_{\mathrm{M}}$ & 18.20 & 46.02* & 13.16 & 2.32 \\
\hline Q.phellos & $2.01 * *$ & -- & -- & -- \\
\hline W. ceracea & $-4.47 * * *$ & -- & -- & -- \\
\hline $\mathrm{R}^{2}$ & 0.593 & 0.213 & 0.028 & 0.041 \\
\hline
\end{tabular}

773 Bold indicates significance at $p<0.05, *: p<0.05, * *: p<0.01$, ***: $p<0.001$. Intercepts marked as

774 significant are different from zero. Full statistical reporting is provided in Table S3. 
776 Table 2: Summary of analyses of all species and species-specific effects of variable temperature

777 heating/cooling rate on $C T_{\mathrm{MIN}}$ and $C T_{\mathrm{MAX}}$.

\begin{tabular}{|c|c|c|c|c|}
\hline $\begin{array}{l}\text { Response: } C T_{\mathrm{MIN}} \\
\text { Fixed effects }\end{array}$ & $\begin{array}{c}\text { All species } \\
\text { Estimate }\end{array}$ & $\begin{array}{l}\text { W. ceracea } \\
\text { Estimate }\end{array}$ & $\begin{array}{c}\text { M. citrina } \\
\text { Estimate }\end{array}$ & $\begin{array}{l}\text { E. rubra } \\
\text { Estimate }\end{array}$ \\
\hline $\begin{array}{l}\text { Cooling rate }=3^{\circ} \mathrm{C} \mathrm{h}^{-1} / \\
\text { E. rubra } \text { (Intercept) }\end{array}$ & $-11.38 * * *$ & $\begin{array}{l}\text { Intercept: } \\
\mathbf{- 4 0 . 8 9 * *}\end{array}$ & $\begin{array}{l}\text { Intercept: } \\
\mathbf{- 1 6 . 8 2} * * *\end{array}$ & $\begin{array}{l}\text { Intercept: } \\
\mathbf{- 1 1 . 5 8 * *}\end{array}$ \\
\hline Cooling rate $=6^{\circ} \mathrm{C} \mathrm{h}^{-1}$ & -0.33 & 0.62 & $-1.81 *$ & -0.15 \\
\hline Cooling rate $=15^{\circ} \mathrm{C} \mathrm{h}^{-1}$ & -0.32 & -0.12 & -0.80 & -0.10 \\
\hline Cooling rate $=30^{\circ} \mathrm{C} \mathrm{h}^{-1}$ & 0.75 & $1.67 * *$ & 0.91 & -0.74 \\
\hline Cooling rate $=60^{\circ} \mathrm{C} \mathrm{h}^{-1}$ & $-1.34 * *$ & 0.75 & $-3.51^{* * * *}$ & $-2.47 * * *$ \\
\hline Cooling rate $=240^{\circ} \mathrm{C} \mathrm{h}^{-1}$ & -0.80 & 0.70 & $-1.74 *$ & $-1.90 * *$ \\
\hline$F_{\mathrm{V}} / F_{\mathrm{M}}$ & -0.89 & 32.04 & 4.66 & 0.12 \\
\hline M. citrina & $-2.18 * * *$ & -- & -- & -- \\
\hline W. ceracea & $-1.53 * *$ & -- & -- & -- \\
\hline Marginal $\mathrm{R}^{2}$ & 0.230 & 0.126 & 0.332 & 0.220 \\
\hline $\begin{array}{l}\text { Response: } C T_{\mathrm{MAX}} \\
\text { Fixed effects }\end{array}$ & $\begin{array}{c}\text { All species } \\
\text { Estimate }\end{array}$ & $\begin{array}{l}\text { W. ceracea } \\
\text { Estimate }\end{array}$ & $\begin{array}{c}\text { M. citrina } \\
\text { Estimate }\end{array}$ & $\begin{array}{l}\text { E. rubra } \\
\text { Estimate }\end{array}$ \\
\hline $\begin{array}{l}\text { Heating rate }=60^{\circ} \mathrm{C}^{-1} / \\
\text { E. rubra (Intercept) }\end{array}$ & $27.79 * * * *$ & $\begin{array}{c}\text { Intercept: } \\
14.87\end{array}$ & $\begin{array}{l}\text { Intercept: } \\
\mathbf{2 7 . 7 9 * * *}\end{array}$ & $\begin{array}{l}\text { Intercept: } \\
\text { 41.75* }\end{array}$ \\
\hline Heating rate $=6^{\circ} \mathrm{C} \mathrm{h}^{-1}$ & -0.68 & $1.60 *$ & $-7.71 * * *$ & 1.38 \\
\hline Heating rate $=15^{\circ} \mathrm{C} \mathrm{h}^{-1}$ & $2.43 * * *$ & $-2.00 * *$ & $-4.68 * * *$ & -1.40 \\
\hline Heating rate $=30^{\circ} \mathrm{C} \mathrm{h}^{-1}$ & $-1.74 * *$ & $-2.11 * * *$ & $-2.10 * *$ & $-1.31 *$ \\
\hline Heating rate $=45^{\circ} \mathrm{Ch}^{-1}$ & $-1.48 * *$ & -0.72 & -0.95 & $-2.68 * * *$ \\
\hline Heating rate $=120^{\circ} \mathrm{C} \mathrm{h}^{-1}$ & 1.00 & $1.78 * *$ & $2.24 *$ & -0.45 \\
\hline Heating rate $=240^{\circ} \mathrm{C} \mathrm{h}^{-1}$ & $2.03 * * *$ & $2.78 * * *$ & $3.76 * * *$ & -0.13 \\
\hline$F_{\mathrm{V}} / F_{\mathrm{M}}$ & $23.79 * * *$ & $38.48 * * *$ & $21.98 * *$ & 5.15 \\
\hline M. citrina & $-1.30 * * *$ & -- & -- & -- \\
\hline W. ceracea & $-1.24 * *$ & -- & -- & -- \\
\hline Marginal $\mathrm{R}^{2}$ & 0.429 & 0.619 & 0.863 & 0.319 \\
\hline
\end{tabular}




\section{Figures}

782 Fig. 1. Experimental system for measuring thermal tolerance limits and representative

783 temperature-dependent chlorophyll fluorescence curves $\left(T-F_{0}\right)$. $(a)$ The Peltier plate-Maxi-

784 Imaging fluorimeter setup for measuring leaf thermal tolerance limits. (b) Representative $T-F_{0}$

785 curve for $C T_{\mathrm{MIN}}$ (inflection point is the $T_{\text {crit }}$ ) where leaf sample temperature $\left({ }^{\circ} \mathrm{C}\right)$ decreases to a

786 point below freezing where the leaf rapidly emits more fluorescence ( $F_{0}$, relative units),

787 indicating the onset of photosynthetic inactivation and freeze dehydration. $(c)$ Representative $T$ -

$788 F_{0}$ curve for $C T_{\text {MAX }}$ (inflection point is the $T_{\text {crit }}$ ) where leaf sample temperature $\left({ }^{\circ} \mathrm{C}\right.$ ) increases

789 beyond tolerance thresholds where the leaf rapidly emits more fluorescence ( $F_{0}$, relative units),

790 indicating the onset of photosynthetic inactivation and potential damage. The example $T-F_{0}$

791 curve for (b) $C T_{\mathrm{MIN}}$ is derived from a leaf sample on dry filter paper cooled at $15^{\circ} \mathrm{C} \mathrm{h}^{-1}$ and for

792 (c) $C T_{\mathrm{MAX}}$ is derived from a leaf sample on dry filter paper heated at $30^{\circ} \mathrm{C} \mathrm{h}^{-1}$. The direction of

793 arrows below the $x$-axes indicates the direction of temperature change.

794

795 Fig. 2. The effect of varying surfaces (dry $v s$ wet filter paper) on the $C T_{\mathrm{MIN}}$ and $C T_{\mathrm{MAX}}$

796 estimates $\left({ }^{\circ} \mathrm{C}\right)$ from basal chlorophyll fluorescence $\left(F_{0}\right.$, relative units) of leaves. We tested how

797 (a) $C T_{\mathrm{MIN}}$ and (b) $C T_{\mathrm{MAX}}$ estimates of leaves from four plant species under standard dry

798 conditions (dry filter paper surface) differed from wet conditions (wet filter paper surface). All

799 estimated were obtained using a standard heating/cooling rate of $60^{\circ} \mathrm{C} \mathrm{h}^{-1}$. Data points are means

800 and $95 \%$ CIs that overlay raw data $(n=12-25$ per treatment $\times$ species combination $)$.

801

802 Fig. 3. The effect of varying heating/cooling rate $\left({ }^{\circ} \mathrm{C} \mathrm{h}^{-1}\right)$ on the $C T_{\mathrm{MIN}}$ and $C T_{\mathrm{MAX}}$ estimates

$803\left({ }^{\circ} \mathrm{C}\right)$ from basal chlorophyll fluorescence $\left(F_{0}\right.$, relative units) of leaves. We tested how $(a) C T_{\mathrm{MIN}}$

804 and (b) $C T_{\text {MAX }}$ estimates of leaves from three plant species were affected by changing the

805 temperature stress at different heating/cooling rates. Data points are means and $95 \%$ CIs that

806 overlay raw data $(n=6-20$ per treatment $\times$ species combination).

807

808 Fig. 4. The effect of heating/cooling rate $\left({ }^{\circ} \mathrm{C} \mathrm{h}^{-1}\right)$ as a continuous variable on the $(a)$ predicted

$809 C T_{\mathrm{MIN}}$ and $(b)$ predicted $C T_{\mathrm{MAX}}$ estimates $\left({ }^{\circ} \mathrm{C}\right)$ in leaves from three plant species. Data points

810 are means and 95\% CIs ( $n=6-20$ per treatment $\times$ species combination) with predicted response

811 curves modelled with quadratic functions separately for each species. 

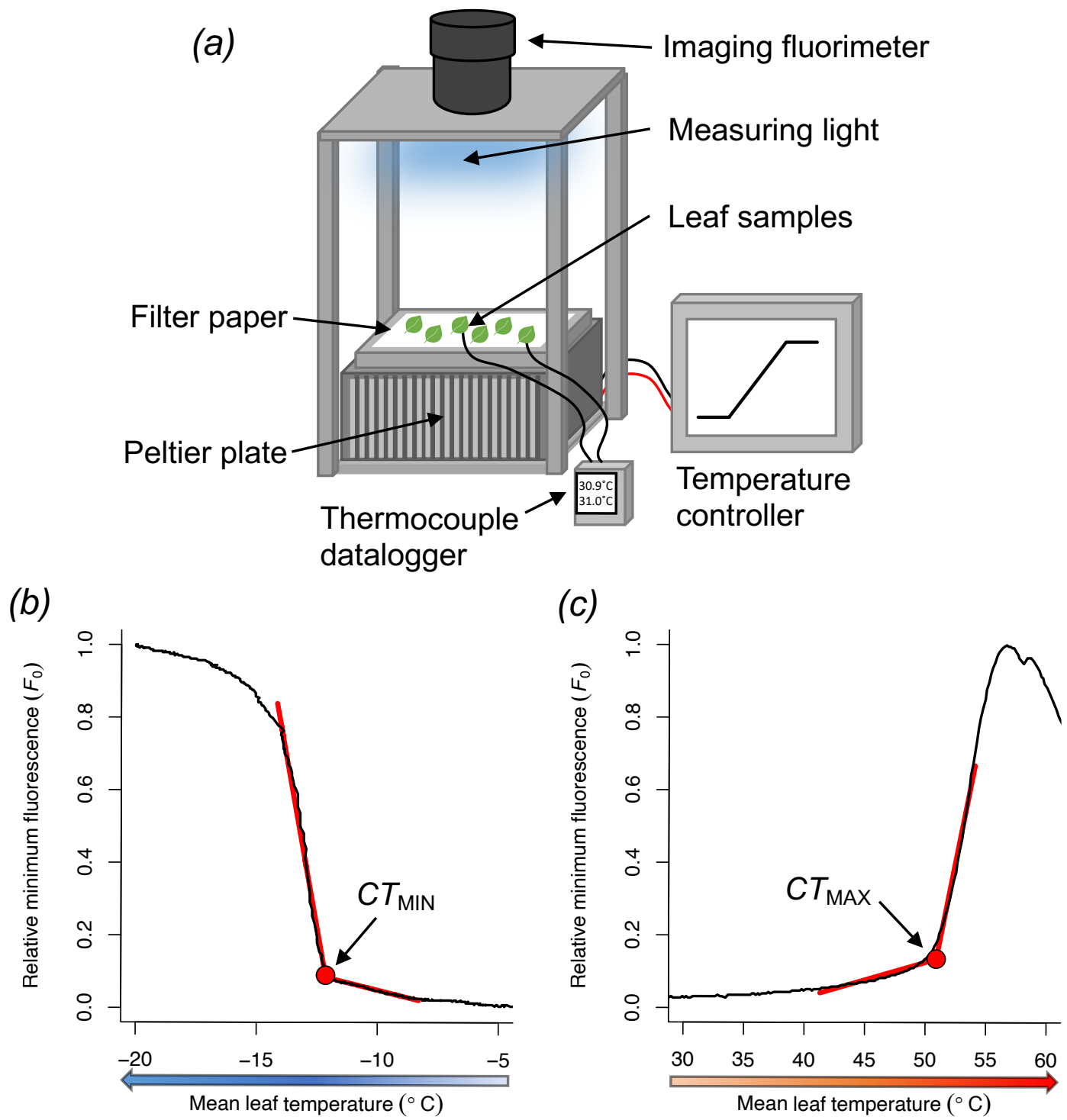
(a)

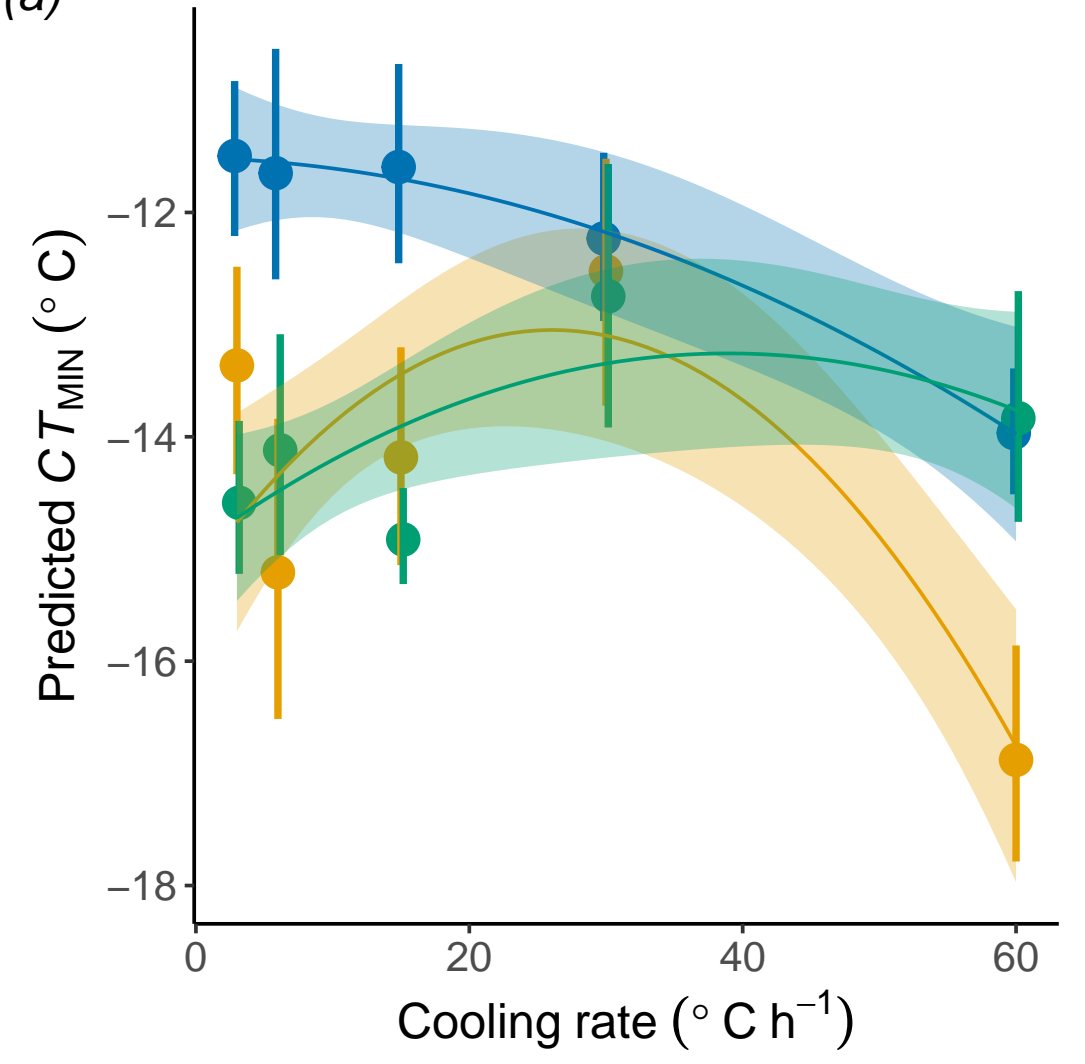

(b)

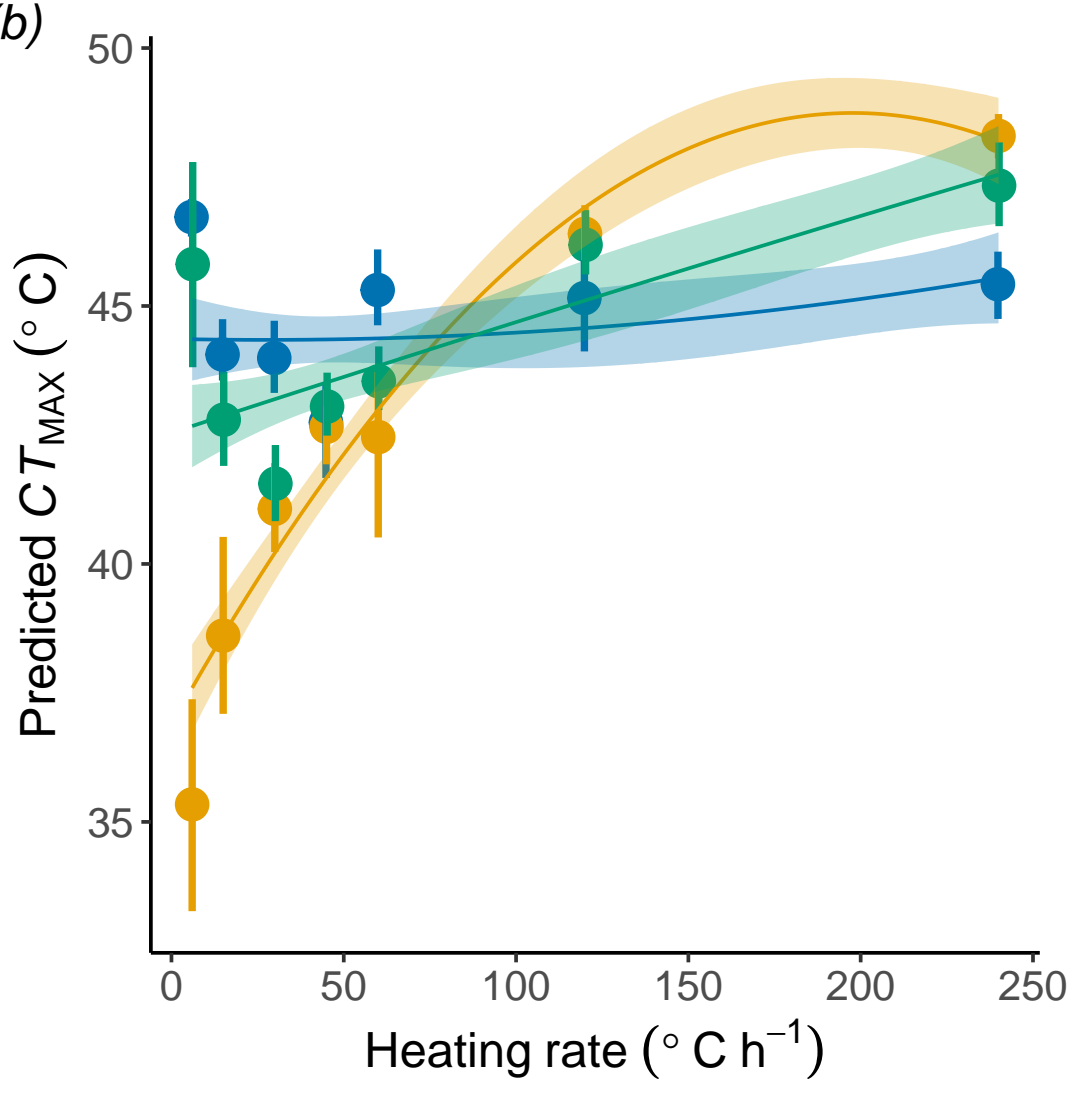

